\title{
X-Abilities and Attributes Based Decision Making in Evaluation and Selection of a Turbine Blade
}

\author{
C. Phaneendra Kiran and Shibu Clement
}

\begin{abstract}
The evaluation and selection of a turbine blade material involves several $x$-abilities and attributes. A designer should consider lifecycle issues as well as design and manufacturing strategies simultaneously at conceptual design stage without missing any of the information. In the proposed methodology the comparison is made between different turbine blade materials based on different $x$-abilities and attributes. The proposed methodology compares the materials using concurrent engineering approach and multi attribute decision making approach (MADM). In the concurrent engineering approach four $x$-abilities namely quality, manufacturing, environment and cost are considered. To maintain uniformity attributes considered in MADM approach are same as concurrent engineering approach. Both the methodologies show that ST12TE is the best material for turbine blade for the given set of attributes and $x$-abilities.
\end{abstract}

Index Terms - Turbine blade material, $\mathrm{x}$-abilities, decision making, concurrent engineering, MADM.

\section{INTRODUCTION}

A number of blades are used in steam turbines ranging from a few centimeters in height in high pressure (HP) turbines to almost one meter long low pressure (LP) turbines. The failure causes for HP and LP turbines are high cyclic fatigue caused by number of factors, centrifugal forces, steady and dynamic stresses, fracture propagation etc. The best way of avoiding these failures is by thorough inspection of raw material and defect free manufacturing of turbine blades. In general, high alloy steels with high chromium content are used for manufacturing of turbine blades. The machinability of these materials is poor and therefore these components are invariably produced by shell-mould-investment casting route directly as net-shaped products. Achieving dimensional accuracy is one of the main challenges of investment casting, on account of shrinkage allowances. Hence, turbine blades are machined using turning, milling and finishing operations. There are different types of blade profiles available. This paper is focused on CNC turning of a specific blade shown in Fig. 1.

The optimal selection of a material for a $\mathrm{CNC}$ turning process, bearing in mind influencing factors like process

Manuscript received October 10, 2014; revised June 12, 2015. The material for these experiments is sponsored by TURBOCAM International, India. We like to thank Mr. Savio Carvalho, Director of the organization for providing the material.

C. Phaneendra Kiran is with the Department of Mechanical Engineering, BITS-Pilani, Hyderabad Campus, Hyderabad, 500078, India (e-mail: cpkiran@Hyderabad.bits-pilani.ac.in).

Shibu Clement is with the Department of Mechanical Engineering, BITS-Pilani, K K Birla Goa Campus, 403786, Goa, India (e-mail: shibu@goa.bits-pilani.ac.in). parameters, surface roughness, environmental effect, material removal rate, blade profile, corrosion resistance, and fatigue strength etc. is a difficult task for the manufacturing industry. Industries require a mathematical tool for the selection of a material for the $\mathrm{CNC}$ turning operation.

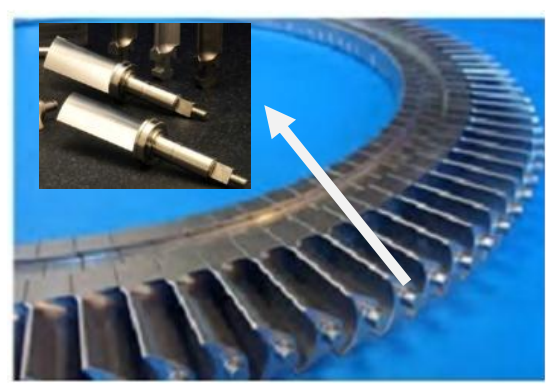

Fig. 1. Turbine blades manufactured at Turbocam, Goa, India (ref: http://www.turbocam.com/blades)

There are several reports in the literature regarding the selection of a specific material for a given application. Sandstorm [1] suggested a two stage selection procedure which includes discriminating and optimizing stages to minimize the number of quality decisions. Ashby [2] proposed material property charts for mechanical and thermal properties, which defines the correlation between the properties in the selection of materials. Rao [3] has proposed a graph theory and matrix algebra based approach in selection of a material for a particular application. In one of the attempts [4], a material selection procedure was suggested based on the combination of two methods. To the best of my knowledge, turbine blade material selection procedure specific to $\mathrm{CNC}$ turning is lacking in the literature.

Albiñana and Vila [5] proposed a framework for integrated materials and process selection in product design. Following an in-depth review of existing studies and the factors that influence decision-making, the flow of reasoning in the process was defined and the relations among the parameters of the whole life cycle to be considered in the conceptual design phase were established. This analysis was then used to define a workflow that breaks the work down into stages and gates, and specified how the preliminary selection was to be performed.

Turbine blades (Fig. 1) are highly stressed components, demanding very precise manufacturing methods. The blade shafts are finish turned on a CNC lathe to obtain accurate profiles and the required surface finish. The dimensional accuracy of the blades and the radius joining at the intersections of two surfaces should be smooth and without under cuts.

During the design phase of turbine blades, it is desirable to have a single numerical index for evaluation of manufacturing. 
The derivation of this numerical index, known as concurrent design index (CDI) this has been presented in the previous work [6]. Based on this concept, the CDI was derived for evaluation of the turning process for three different materials (ST 17-4PH, ST 12TE, and ST T17/13W) used in the manufacturing of turbine blades. In deriving this CDI, different $\mathrm{x}$-abilities like design for manufacturing (DFM), design for quality (DFQ), design for environment (DFE) and Design for cost (DFC) were used. In the next part a 3-stage selection procedure is described for the decision-making process which is presented in selection of different application [7]. TOPSIS (technique for order preference by similarity to ideal solution)-an MADM tool as well as graphical methods, namely line graph and spider graph, are used in quality evaluation of materials by considering all responsible attributes in totality. The methodology is applied in quality evaluation and selection of turbine blade material for the CNC turning process.

\section{X-ABILITIES BASED ANALYSIS}

In evaluation, comparison and selection of a turbine blade material for $\mathrm{CNC}$ turning process different $\mathrm{x}$-abilities should be considered simultaneously. The $\mathrm{x}$-abilities considered in the present study are design for manufacturing(DFM), design for quality (DFQ), design for environment (DFE), and design for cost (DFC) discussed as follows.

\section{A. Design for Manufacturing (DFM)}

Machining is the most widespread metal shaping process in mechanical manufacturing industry. Machining operations such as turning, milling, boring, drilling and shaping, waste a large amount of raw material as well as time, and consume a large amount of money annually [8]. Out of these machining processes, turning remains the most important operation used to shape metals because in turning, the conditions of operation are varied. Increasing productivity and reducing manufacturing cost have always been critical to successful business [9]. In turning, higher values of cutting parameters offer opportunities for increasing productivity but it also involves a greater risk of deterioration in surface quality and tool life [8], [10]-[13]. Optimal combinations of turning parameters are required to obtain the best surface on the work pieces. The basic turning parameters in deciding the quality of the turbine shafts are speed $(V)$, feed $(f)$ and depth of cut $(a)$. Other factors which influence manufacturability include tool geometry and materials. All the cutting parameters would come under design parameter X3DP9 [6]. The methodology is applied in evaluation of turbine blade materials for CNC turning. In this, geometry was maintained constant for turning of all the three materials. The optimal combination of the basic parameters obtained using central composite design (CCD) method, a variant of design of experiment, and the values were substituted here to obtain the DFM index of each material. The DFM permanent matrix was defined as:

$$
\mathrm{DFM}=\left[\begin{array}{ccc}
V & e_{12} & e_{13} \\
e_{21} & f & e_{23} \\
e_{31} & e_{32} & a
\end{array}\right]
$$

where $V=$ speed, $f=$ feed, and $a=$ depth of cut, and $e_{i j}$ represents the interaction between these parameters. The units and dimensions of the diagonal elements in DFM were different for different parameters. To make them non-dimensional numbers, individual parameters were divided with the maximum value considered in the experiment. For example, in all the experiments, the maximum speed considered was $209 \mathrm{~m} / \mathrm{min}$, so the non-dimensional velocity component for the material 1 was V1/209. The interactions between different cutting parameters were obtained from the experiments conducted [14]. To bring the interaction values into a single range, all the values were normalized. In the experimental results, the interactions obtained were symmetric about the diagonal i.e. $e_{i j}=e_{j i}$. The optimum parameter combination to obtain maximum surface quality for the materials [15] and the normalized values are listed in Table I.

TABLE I: NORMALIZATION OF CUTTING PARAMETERS FOR DIFFERENT

\begin{tabular}{|l|l|l|l|}
\hline \multicolumn{1}{|c|}{ Materials } & ST 12TE & ST T17/13W & ST 17-4 PH \\
\hline Parameters & & & \\
\hline Speed $(V) \mathrm{m} / \mathrm{min}$ & 175 & 209 & 175 \\
\hline Feed $(f) \mathrm{mm} / \mathrm{min}$ & 200 & 150 & 100 \\
\hline Depth of cut $(a) \mathrm{mm}$ & 0.500 & 0.875 & 0.500 \\
\hline$V / \mathrm{Vmax}(=209)$ & 0.837 & 1 & 0.837 \\
\hline$f / \mathrm{fmax}(=234)$ & 0.854 & 0.640 & 0.427 \\
\hline$a / \mathrm{amax}(1.5)$ & 0.330 & 0.580 & 0.330 \\
\hline$e_{12}(V \times f)$ & 0.005 & 0.582 & 1 \\
\hline$e_{13}(V \times a)$ & 0.156 & 0.030 & 1 \\
\hline$e_{23}(f \times a)$ & 1 & 0.145 & 0.016 \\
\hline
\end{tabular}

After substituting the normalized values of cutting parameters and the interaction values into the equation (1), an index for each material was obtained by applying permanent function to the matrix and is as follows:

$$
\begin{aligned}
\mathrm{DFM}_{\text {ST12TE }}=\operatorname{per}\left[\begin{array}{ccc}
0.837 & 0.005 & 0.156 \\
0.005 & 0.854 & 1 \\
0.156 & 1 & 0.33
\end{array}\right]=1.095 \\
\mathrm{DFM}_{\mathrm{ST} \mathrm{T17/13W}}=\operatorname{per}\left[\begin{array}{ccc}
1 & 0.582 & 0.030 \\
0.582 & 0.64 & 0.145 \\
0.030 & 0.145 & 0.58
\end{array}\right]=0.5943 \\
\mathrm{DFM}_{\mathrm{ST} \mathrm{17-4PH}}=\operatorname{per}\left[\begin{array}{ccc}
0.837 & 1 & 1 \\
1 & 0.427 & 0.016 \\
1 & 0.016 & 0.333
\end{array}\right]=0.913
\end{aligned}
$$

A high value of the index indicates that a particular material is highly suited for a manufacturing process.

\section{B. Design for Quality (DFQ)}

Surface finish of a turbine blade is an important parameter in the turning process. It is a characteristic that could influence the performance of the finished product and 
production costs. Various failures, sometimes catastrophic, leading to high costs have been attributed to the surface finish of the components in question [11]. Also cutting forces are critically important in turning operations because cutting force correlate strongly with cutting performance such as surface accuracy, tool wear, tool breakage, cutting temperature, self-excited and forced vibrations, etc. The resultant cutting force is generally resolved into three components, namely, feed force, cutting force and thrust force. In this case the dimensional accuracy (X8DP5) of turned steel depends on factors like surface finish (Ra) cutting force (fc), thrust force $\left(f_{T}\right)$ and tool wear (TW). Hence, these four parameters were considered under the $\mathrm{x}$-ability DFQ. The DFQ permanent matrix was written as below:

$$
\mathrm{DFQ}=\operatorname{per}\left[\begin{array}{cccc}
\frac{R_{a}}{\left(R_{a}\right)_{\max }} & e_{12} & e_{13} & e_{14} \\
e_{21} & \frac{f_{c}}{\left(f_{c}\right)_{\max }} & e_{23} & e_{24} \\
e_{31} & e_{32} & \frac{f_{T}}{\left(f_{T}\right)_{\max }} & e_{34} \\
e_{41} & e_{42} & e_{43} & \frac{T_{W}}{\left(T_{W}\right)_{\max }}
\end{array}\right]
$$

The parameters considered under DFQ are the responses; hence it is not possible to find the interactions using DOE. Each interaction was thus assigned with either 1 or 0 depending on whether the interaction existed or not. The value of $R_{a}$ depends on the $f_{c}, f_{T}$, and $T_{w}$, so the interaction between them $\left(e_{12}, e_{13}\right.$ and $\left.e_{14}\right)$ was taken as 1 . The cutting forces are independent of each other, hence interaction between them $\left(e_{23}\right)$ was considered as 0 . The tool wear depends on the rest of three factors, so these interactions $\left(e_{14}\right.$, $e_{24}$ and $e_{34}$ ) were considered as 1 . In the permanent DFQ matrix, it was assumed that interactions are symmetric about the diagonal i.e. $e_{i j}=e_{j i}$. The DFQ indices for different materials were calculated as follows:

$$
\begin{aligned}
& \text { DFQ }_{\text {ST12TE }}=\operatorname{per}\left[\begin{array}{cccc}
0.388 & 1 & 1 & 1 \\
1 & 1 & 0 & 1 \\
1 & 0 & 0.76 & 1 \\
1 & 1 & 1 & 0.4
\end{array}\right]=9.78 \\
& \text { DFQ }_{\text {ST T17/13W }}=\operatorname{per}\left[\begin{array}{cccc}
1 & 1 & 1 & 1 \\
1 & 0.86 & 0 & 1 \\
1 & 0 & 0.8 & 1 \\
1 & 1 & 1 & 1
\end{array}\right]=12.06 \\
& \text { DFQ }_{\text {ST 17-4PH }}=\operatorname{per}\left[\begin{array}{ccccc}
0.787 & 1 & 1 & 1 \\
1 & 0.767 & 0 & 1 \\
1 & 0 & 1 & 1 \\
1 & 1 & 1 & 0.2
\end{array}\right]=9.39
\end{aligned}
$$

All the diagonal elements of DFQ were found to have a negative effect on the quality of the turned product. Hence, the higher the values of DFQ index, the lower the quality of turned work piece.

\section{Design for Environment (DFE)}

As the importance of minimizing the environmental burden of each process is becoming more and more evident and essential, it is imperative that these effects be considered during the design phase. The basic parameters effecting the environment include machine tool electricity power consumption (PC), the material removal rate (MRR) and the coolant consumption.

The power consumption of a machine tool for a turning operation depends on different motors like servo motor, spindle motor, spindle coolant circulating motor, coolant pump, chip conveyer, auto tool changing motor, tool magazine, and machine tool standby power consumption. The power consumption of peripheral devices for this operation is measured using the operation duration time and the power rating of particular device in $\mathrm{kWh}$.

In case of water-miscible cutting fluid, water is generally used to enhance the performance and is circulated in machine tools by coolant pumps until replaced. During this period, some coolants are eliminated by adhering to metal chips and extra coolant is supplied to compensate this. The reduction in dilution fluid (water) due to vapor must also be considered [12] in estimating total coolant.

The amount of material removed is equal to amount of raw material wasted. A lot of resources are wasted in preparing the raw material billets like furnaces used for processing raw material, transportation cost, inventory cost, etc. The removed chip wastes energy by carrying the lubricant, heat (proportional to electricity), tool wear, build up edge, etc. Hence, the $M R R$ is considered as one of the parameter in calculating the DFE index. The permanent matrix of DFE was written as follows:

$$
\mathrm{DFE}=\operatorname{per}\left[\begin{array}{ccc}
\frac{M R R}{(M R R)_{\max }} & e_{12} & e_{13} \\
e_{21} & \frac{P C}{(P C)_{\max }} & e_{23} \\
e_{31} & e_{32} & \frac{C C}{(C C)_{\max }}
\end{array}\right]
$$

In the above expression $M R R=$ material removal rate $\mathrm{cm}^{3} / \mathrm{min}, P C=$ Power consumption $\mathrm{kWh}$, and $C C=$ coolant consumption in $C C$. All the diagonal elements were normalized to make them units free and also to bring them in a common scale. In the off-diagonal elements, the $M R R$ interacted with $P C$ and $C C$ (increase in $M R R$ will increase $P C$ and $C C$ ), therefore the value considered for this interaction was 1 . There will be no direct interaction between $P C$ and $C C$ so this interaction value was considered as 0 . The DFE index for the given materials were calculated as follows:

$$
\mathrm{DFE}_{\mathrm{ST} 12 \mathrm{TE}}=\operatorname{per}\left[\begin{array}{ccc}
0.625 & 1 & 1 \\
1 & 0.7 & 0 \\
1 & 0 & 0.75
\end{array}\right]=1.778
$$

$$
\operatorname{DFE}_{\mathrm{ST} T 17 / 13 \mathrm{~W}}=\operatorname{per}\left[\begin{array}{ccc}
1 & 1 & 1 \\
1 & 1 & 0 \\
1 & 0 & 0.875
\end{array}\right]=2.75
$$




$$
\mathrm{DFE}_{\mathrm{ST} 17-4 \mathrm{PH}}=\operatorname{per}\left[\begin{array}{ccc}
0.5625 & 1 & 1 \\
1 & 0.6 & 0 \\
1 & 0 & 1
\end{array}\right]=1.937
$$

All diagonal elements of the DFE have a negative effect on the environment. Hence, the higher the values of DFE index, the greater the impact on the environment.

\section{Design for Cost (DFC)}

Cost is an important criterion in production of a turbine blade. Therefore, it is required to consider different costs at the design phase. The non-dimensional cost components taken into consideration for development of DFC matrix were:

- Raw material cost ratio $\left(C_{R}\right)$

- Tooling cost ratio $\left(C_{T}\right)$

- Processing cost ratio $\left(C_{P}\right)$

- Labor cost ratio $\left(C_{L}\right)$

The material costs were obtained from vendors/supplier of the material, while the other costs could be estimated by the manufacturer by taking into account factors like machine utilization cost, machines capability to produce number of components over its useful life, cost of operating the CNC lathe, overall labor charges, etc. In the present analysis, the overhead cost and profits have not been considered.

The work reported in the literature indicates that near net shaped casting is the best alternative for the machining of these steels. Hence, the cost of near net shaped casting was taken as the benchmarking cost for production of turbine blade. The relative cost ratio was obtained by dividing the total cost of benchmarked product by individual cost component of the product. It should be noted that cost components were calculated per unit/product basis. It was evident that individual cost components $C_{R}, C_{T}, C_{P}$ and $C_{L}$ were maximized when the individual cost components were minimized. This corroborates the idea that minimizing the cost components leading to minimizing the total cost. The costs of different materials are presented in Table II.

TABLE II: DIFFERENT COSTS CONSIDERED FOR EACH MATERIAL IN MANUFACTURING OF TURBINE BLADE

\begin{tabular}{|l|l|l|l|}
\hline Material & ST 12TE & ST T17/13W & ST 17-4PH \\
\hline Cost/kg (INR) & 150 & 155 & 168 \\
\hline Mass of turbine blade(kg) & 3 & 3.5 & 2.8 \\
\hline $\begin{array}{l}\text { Raw material cost } \\
\text { INR(1.5xmass of blade) }\end{array}$ & 675 & 814 & 705 \\
\hline Tooling cost, INR & 100 & 90 & 120 \\
\hline Processing cost, INR & 148 & 162 & 153 \\
\hline Labor cost, INR & 29.6 & 32.4 & 30.6 \\
\hline Total cost, INR & 952.6 & 1098.4 & 1008.6 \\
\hline
\end{tabular}

\section{1) Raw material cost ratio $\left(C_{R}\right)$}

The raw material cost ratio is based on the mass of the final turbine blade multiplied by the factor 1.5 [13]. This factor accounts for wastage of material in the machining. The cost of the steel was taken from the vendors based on the prices of the steel on the day of study. The cost ratio of raw material is defined as:

$$
C_{R}=\frac{\text { Total cost of near net shaped product }}{\text { Cost of the raw material }}
$$

\section{2) Tooling cost ratio $\left(C_{T}\right)$}

The tooling cost of a turbine blade includes the partial cost of the tool insert used in turning, partial cost of finishing tool, and the partial cost of milling tool if any used in the process. The term partial cost indicates that if the tool insert is used for ten work pieces and the cost of each insert is INR 100, then partial cost of the tool insert is INR 10 for each work piece. The tooling cost ratio is defined as

$$
C_{T}=\frac{\text { Total cost of near net shaped product }}{\text { Cost of the tooling }}
$$

\section{3) Processing cost ratio $\left(C_{P}\right)$}

The processing cost of a turbine blade includes cost of the auxiliary processes applied on the product. For example, heat treatment of the product, die penetration test for finding out the surface defects, etc. The power consumption for each work piece is also counted in this cost. The processing cost ratio is defined as follows

$$
C_{P}=\frac{\text { Total cost of near net shaped product }}{\text { Cost of the processing }}
$$

\section{4) Labor cost ratio $\left(C_{L}\right)$}

The labor cost is assumed as $20 \%$ of the processing cost per component. With increase in the number of auxiliary processes the labor cost also increases. The labor cost ratio is defined as

$$
C_{L}=\frac{\text { Total cost of near net shaped product }}{\text { Cost of the Labor }}
$$

After calculating the cost ratios from the equations (13) to (16), the values were substituted in the design for cost matrix defined as follows:

$$
\mathrm{DFC}=\operatorname{per}\left[\begin{array}{llll}
C_{R} & e_{12} & e_{13} & e_{14} \\
e_{21} & C_{T} & e_{23} & e_{24} \\
e_{31} & e_{32} & C_{P} & e_{34} \\
e_{41} & e_{42} & e_{43} & C_{L}
\end{array}\right]
$$

In this matrix diagonal elements represents the cost ratios of each material and off-diagonal elements represent the interactions between the costs. As the cost ratios are independent of each other, the values of eij are substituted as zeroes. The DFC matrix for each material is defined as follows:

$$
\begin{gathered}
\mathrm{DFC}_{\mathrm{ST} 12 \mathrm{TE}}=\operatorname{per}\left[\begin{array}{cccc}
1.04 & 0 & 0 & 0 \\
0 & 7 & 0 & 0 \\
0 & 0 & 4.73 & 0 \\
0 & 0 & 0 & 23.65
\end{array}\right]=814.374 \\
\mathrm{DFC}_{\mathrm{ST} T 17 / 13 \mathrm{~W}}=\operatorname{per}\left[\begin{array}{cccc}
0.86 & 0 & 0 & 0 \\
0 & 7.78 & 0 & 0 \\
0 & 0 & 4.32 & 0 \\
0 & 0 & 0 & 21.6
\end{array}\right]=624.332
\end{gathered}
$$




$$
\mathrm{DFC}_{\text {ST 17-4PH }}=\operatorname{per}\left[\begin{array}{cccc}
0.99 & 0 & 0 & 0 \\
0 & 5.83 & 0 & 0 \\
0 & 0 & 4.58 & 0 \\
0 & 0 & 0 & 22.88
\end{array}\right]=604.819
$$

All the diagonal elements of DFC matrix were larger-the-better parameters. Hence, it could be concluded that DFC should be maximized for the production of best turbine blade at optimal cost.

\section{E. Design for $X(D F X)$}

The calculated indices of different $X$-abilities namely DFM, DFQ, DFE and DFC were substituted in the overall DFX matrix to obtain the CDI. In substituting the values of DFQ and DFE, the reciprocals were used in order to minimizing the effects. The DFX matrix is defined as

$$
\mathrm{DFX}=\operatorname{per}\left[\begin{array}{cccc}
D F M & 0 & 0 & 0 \\
0 & \frac{1}{D F Q} & 0 & 0 \\
0 & 0 & \frac{1}{D F E} & 0 \\
0 & 0 & 0 & D F C
\end{array}\right]
$$

The permanent function of the DFX matrix would yield a single index called concurrent design index (CDI). Table III shows the different design indices values and the CDI in the last column.

TABLE III: CDI INDICES OF THE CONSIDERED MATERIALS

\begin{tabular}{|l|l|l|l|l|l|}
\hline Material & DFM & 1/DFQ & $1 /$ DFE & DFC & CDI \\
\hline ST 12TE & 1.095 & 0.102 & 0.562 & 814.374 & 51.12 \\
\hline $\begin{array}{l}\text { ST } \\
\text { T17/13W }\end{array}$ & 0.5943 & 0.083 & 0.364 & 624.332 & 11.21 \\
\hline ST17-4PH & 0.913 & 0.106 & 0.516 & 604.819 & 30.2 \\
\hline
\end{tabular}

\section{F. Results and Discussion}

The CDI considered for each material was a contribution of separate design parameters. A high value of the CDI would indicate a better choice of material for the $\mathrm{CNC}$ machining of turbine blade. In the overall ST 12TE obtained, the highest CDI equaled 51.12. For the individual indices, ST 12TE had the highest indices for DFM, DFE and DFC. The material ST17-4PH had highest index for the quality. This can be attributed to high surface finish for the specified combination of cutting parameters, and low cutting and thrust forces. Otherwise, ST17-PH was found to be a harder material to machine than the others. Material ST T17/13W had the lowest value of DFX as compared to others. This material had the lowest surface finish at the highest speed as compared to the other materials. In general at higher speed the surface finish would be higher due to large amount of material removal rate. The lower DFX index of this material could also be attributed to consistently lower values of DFM and DFC and higher values of DFE and DFQ.

\section{MADM BASED EVALUATION}

In this section the methodology derived in the previous communication (Kiran et al., 2011b) was applied in the selection of turbine blade material for CNC turning process. The manufacturer would like to select the most suitable material for turning of a turbine blade, based on the multiple attributes, while considering all pertinent attributes simultaneously. In DFX based evaluation the interaction between the parameters are considered as the off-diagonal elements. It is also important to consider the relative importance of attributes. In the MADM approach the evaluation and selection is done based on the attributes and their relative importance.

\section{A. Stage 1-Elimination Search}

In order to reduce a huge list of materials to a manageable number, only steels available in the inventory were considered. These materials were filtered to a manageable number by machining at the following conditions and retaining only those materials that had surface roughness less than $5.5 \mu \mathrm{m}$.

1) Speed $=75 \mathrm{~m} / \mathrm{min}$

2) Feed $=100 \mathrm{~mm} / \mathrm{min}$

3) Depth of cut $=0.5 \mathrm{~mm}$

4) Coolant should be present

5) Tool insert is CNMG $120408 \mathrm{MN}$

6) Machined length of the work piece is $30 \mathrm{~mm}$

7) Minimum Chromium percentage $15 \%$

Following the elimination search, the few alternatives that remained were further evaluated. Before proceeding for TOPSIS, the pertinent attributes for the selection process are listed in Table IV.

TABLE IV: PERTINENT ATTRIBUTES OF TURNING OPERATION AND

\begin{tabular}{|l|c|c|c|c|c|c|}
\hline \multicolumn{1}{|c}{ Material } & $\begin{array}{c}R_{a} \text { (micro } \\
\text { meter) }\end{array}$ & $F_{c}(N)$ & $F_{t}(N)$ & $P C(W)$ & $\begin{array}{c}M R R \\
\left(\mathrm{~cm}^{3} / \mathrm{min}\right)\end{array}$ & $T C(I N R)$ \\
\hline $\begin{array}{l}\text { ST 12TE } \\
(\mathrm{A} 1)\end{array}$ & 1.54 & 48.23 & 109.50 & 1280 & 1.5 & 952.0 \\
\hline $\begin{array}{l}\text { ST 17/13W } \\
(\mathrm{A} 2)\end{array}$ & 1.203 & 56.73 & 106.34 & 1350 & 1.4 & 1098.4 \\
\hline $\begin{array}{l}\text { ST 17-4PH } \\
(\mathrm{A} 3)\end{array}$ & 2.13 & 61.50 & 120.17 & 1560 & 1.3 & 900.0 \\
\hline $\begin{array}{l}9 \mathrm{SMnPb} 28 \mathrm{k} \\
(\mathrm{A} 4)\end{array}$ & 3.59 & 80.17 & 150.00 & 1650 & 2.5 & 1200.0 \\
\hline $\begin{array}{l}42 \mathrm{CrMo} \text { steel } \\
(\mathrm{A} 5)\end{array}$ & 2.50 & 65.20 & 124.21 & 1580 & 2.1 & 1108.0 \\
\hline
\end{tabular}

The pertinent attributes are average surface roughness $\left(R_{a}\right)$ in micrometer, cutting and thrust forces $F_{c}, F_{t}$ in $N$, power consumption $(P C)$ in Watts, material removal rate $(M R R)$ in $\mathrm{cm}^{3} / \mathrm{s}$, and tool cost in Indian rupees.

\section{B. Stage 2-TOPSIS Based Evaluation and Selection Procedure}

\section{1) Decision matrix}

The decision matrix for the alternative materials was formulated from the Table IV and is given in matrix form as follows.

$A_{1}$
$A_{2}$
$A_{3}$
$A_{4}$
$A_{5}$$\left[\begin{array}{cccccc}1.54 & 48.23 & 109.50 & 1280 & 1.5 & 952 \\ 1.20 & 56.73 & 106.34 & 1350 & 1.4 & 1098.4 \\ 2.13 & 61.50 & 120.17 & 1560 & 1.3 & 900 \\ 3.59 & 80.17 & 150.00 & 1650 & 2.5 & 1200 \\ 2.50 & 65.20 & 124.21 & 1580 & 2.1 & 1108\end{array}\right]$


This matrix could contain real values of the attributes with different units. Each row in the matrix $D$ represented the attribute values of a particular alternative.

\section{2) Normalized matrix}

Each element of the matrix was processed to obtain a normalized matrix $R$.

$$
R=\left[\begin{array}{llllll}
0.2937 & 0.3410 & 0.3981 & 0.3840 & 0.3686 & 0.4026 \\
0.2294 & 0.4011 & 0.3866 & 0.4050 & 0.3440 & 0.4646 \\
0.4062 & 0.4348 & 0.4369 & 0.4680 & 0.3195 & 0.3806 \\
0.6847 & 0.5668 & 0.5453 & 0.4949 & 0.6143 & 0.5075 \\
0.4768 & 0.4610 & 0.4515 & 0.4740 & 0.5160 & 0.4686
\end{array}\right]
$$

In the above matrix the values of attributes are reduced to uniform scale ranges from 0 to 1 .

\section{3) Relative importance matrix}

The relative importance matrix A for this application was derived and is as follows:

$$
A=\left[\begin{array}{cccccc}
1 & 1 & 1 & 1.5 & 1 & 1 \\
1 & 1 & 1 & 1 & 0.5 & 1 \\
1 & 1 & 1 & 1 & 0.5 & 1 \\
0.67 & 1 & 1 & 1 & 0.5 & 1 \\
1 & 2 & 2 & 2 & 1 & 1 \\
1 & 1 & 1 & 1 & 1 & 1
\end{array}\right]
$$

In the above expression diagonally symmetric values were taken reciprocal to each other. Based on the importance of one attribute over the other, the values of off-diagonal elements were assigned. For example, element $a_{14}$ was assigned a value 1.5 . This means that the first attribute is 1.5 times important than the fourth attribute. The diagonally opposite element i.e. $a_{21}$ was assigned reciprocal of $a_{12}, 0.67$. Similarly, other values were also assigned.

- Weight vector:

The Eigen spectrum of relative importance matrix A was determined based on the equation (24) and was written as:

$$
(A-\lambda I)=\left[\begin{array}{cccccc}
1-\lambda & 1 & 1 & 1.5 & 1 & 1 \\
1 & 1-\lambda & 1 & 1 & 0.5 & 1 \\
1 & 1 & 1-\lambda & 1 & 0.5 & 1 \\
0.67 & 1 & 1 & 1-\lambda & 0.5 & 1 \\
1 & 2 & 2 & 2 & 1-\lambda & 1 \\
1 & 1 & 1 & 1 & 1 & 1-\lambda
\end{array}\right]=0
$$

Solving the equation (25) for $\lambda$ yielded:

$$
\begin{gathered}
\lambda=(6.0841,-0.0429+0.6667 i,-0.0429-0.6667 i, 0.0008+ \\
0.2465 i, 0.0008-0.2465 i,-0.0000)
\end{gathered}
$$

Using the maximum Eigen value and solving the following equation:

$$
\begin{aligned}
& \left(A-\lambda_{\max } I\right) W= \\
& {\left[\begin{array}{cccccc}
-5.0841 & 1 & 1 & 1.5 & 1 & 1 \\
1 & -5.0841 & 1 & 1 & 0.5 & 1 \\
1 & 1 & -5.0841 & 1 & 0.5 & 1 \\
0.67 & 1 & 1 & -5.0841 & 0.5 & 1 \\
1 & 2 & 2 & 2 & -5.0841 & 1 \\
1 & 1 & 1 & 1 & 1 & -5.0841
\end{array}\right]\left[\begin{array}{c}
w_{1} \\
w_{2} \\
w_{3} \\
w_{4} \\
w_{5} \\
w_{6}
\end{array}\right]=0}
\end{aligned}
$$

Calculating weights for each attributes using the equation (26) and as follows:

$w_{1}=0.1755 ; w_{2}=0.1451 ; w_{3}=0.1451 ; w_{4}=0.1356 ; w_{5}=$ $0.2344 ; w_{6}=0.1644$.

\section{4) Weighted normalized decision matrix}

After substituting the values of $R$, the obtained weighted normalized decision matrix $Q$ was as follows:

$$
\begin{aligned}
q_{i j} & =\left[r_{i j}\right] *\left[w_{j}\right], \text { where } i=1,2 . .5, j=1,2, \ldots, 6 \\
Q & =\left[\begin{array}{lllllll}
0.0515 & 0.0495 & 0.0578 & 0.0521 & 0.0864 & 0.0662 \\
0.0403 & 0.0582 & 0.0561 & 0.0549 & 0.0806 & 0.0764 \\
0.0713 & 0.0631 & 0.0634 & 0.0635 & 0.0749 & 0.0626 \\
0.1202 & 0.0822 & 0.0791 & 0.0671 & 0.144 & 0.0834 \\
0.0837 & 0.0669 & 0.0655 & 0.0643 & 0.1210 & 0.0770
\end{array}\right]
\end{aligned}
$$

- Ranking procedure:

1) Positive ideal and negative ideal solutions

The values of Positive ideal and negative ideal solution for each alternative were found to be:

$$
P^{*}=(0.0403,0.0495,0.0561,0.0521,0.144,0.0626)
$$

$$
P^{-}=(0.1202,0.0822,0.0791,0.0671,0.0749,0.0834)
$$

2) Determination of separation measures

Separation measures for the four alternatives were calculated based on the method described in equation (28) and (29). The separation measures obtained were:

$$
\begin{aligned}
& S_{1}^{*}=0.0588 S_{2}^{*}=0.0655 S_{3}^{*}=0.0781 S_{4}^{*}=0.0930 S_{5}^{*}=0.0562 \\
& S_{1}^{-}=0.083 S_{2}^{-}=0.0879 S_{3}^{-}=0.0587 S_{4}^{-}=0.0691 S_{5}^{-}=0.0627
\end{aligned}
$$

3) Relative closeness to positive benchmark indices

The relative closeness to positive benchmark indices were calculated based on the equation discussed earlier communication (Kiran, 2011b). Indices for all the four alternatives were:

$$
C_{1}^{*}=0.5853 C_{2}^{*}=0.5730 C_{3}^{*}=0.4291 C_{4}^{*}=0.4263 C_{5}^{*}=0.5273
$$

This index is a measure of suitability of the material for a particular machining operation.

\section{Stage 3-Ranking and Final Decision Making}

The ranking was carried out based on the values of relative closeness to benchmark indices. The alternative with the highest value of $C^{*}$ was assigned the first rank and the lowest value was assigned the last rank. For the linear graph and spider plot, the lowest value was assigned the first rank. Ranking of all the six alternatives based on the three methods visually TOPSIS, line graph, and spider diagram are listed in Table V. A minor discrepancy was observed in the rankings as obtained by linear and spider plot and that obtained from the TOPSIS analysis. This may be attributed to the fact that in calculating the area below the linear and spider chart most of the attributes were smaller-the-better and one attribute was 
larger-the-better. The area under the larger-the-better attribute was maximum-the-better and area under smaller-the-better attribute is minimum-the-better, but the areas given in Table $\mathrm{V}$ do not distinguishing between these two.

All the three methods showed that the optimum material was ST 12TE based on the pertinent attributes and the relative importance matrix supplied by the customer. Though all the three methods showed almost similar ranking order, the TOPSIS method was found to be most accurate. This is because, in TOPSIS, the ranking ensures that the highest ranked alternative is closest to the ideal and farthest from the worst solution. Graphical methods ensure that the solution is closer to the ideal solution, but do not ensure that it is farthest from the worst solution. As compared with graphical methods, TOPSIS differentiates the larger-the-better and smaller-the-better attributes.

The first rank status of ST 12TE can be attributed to its low surface roughness which ensures high machinabilty, low cutting forces, low power consumption, high material removal rate and low total cost. The best suited material, ST $12 \mathrm{TE}$, is an austenitic steel having high corrosion resistance and machinability. This result also corroborates with the ranking derived in Section II based on DFX. Hence, in this study, ST 12TE was identified and recommended as the best suited material for the turbine blade CNC turning application.

TABLE V: RANKING OF ALTERNATIVE MATERIALS FOR CNC TURNING PROCESS

\begin{tabular}{|c|c|c|c|c|c|c|}
\hline $\begin{array}{l}\text { Alternative material } \\
\text { (Ai) }\end{array}$ & $\begin{array}{l}\text { TOPSIS Relative } \\
\text { closeness to bench } \\
\text { mark system, } \mathrm{C}_{\mathrm{i}}^{*}\end{array}$ & $\begin{array}{l}\text { Rank based } \\
\text { on } \mathrm{C}_{\mathrm{i}}^{*}\end{array}$ & $\begin{array}{l}\text { COS based on Line } \\
\text { Graph, } \operatorname{COS}_{\mathrm{i}}^{\mathrm{QL}}\end{array}$ & $\begin{array}{l}\text { Rank based on } \\
\operatorname{COS}_{\mathrm{i}}^{\mathrm{QL}}\end{array}$ & $\begin{array}{l}\text { COS based on spider } \\
\text { diagram, } \operatorname{COS}_{\mathrm{i}}^{\mathrm{QS}}\end{array}$ & $\begin{array}{l}\text { Rank based on } \\
\mathrm{OS}_{\mathrm{i}}{ }^{\mathrm{QS}}\end{array}$ \\
\hline ST 12TE (A1) & 0.5853 & 1 & 0.3188 & 1 & 0.0099 & 1 \\
\hline ST 17/13W(A2) & 0.573 & 2 & 0.327 & 2 & 0.01 & 2 \\
\hline ST 17-4PH (A3) & 0.4291 & 4 & 0.3438 & 3 & 0.0119 & 3 \\
\hline 9SMnPb28k (A5) & 0.4263 & 5 & 0.4883 & 5 & 0.0241 & 5 \\
\hline 42CrMo steel (A6) & 0.5273 & 3 & 0.4125 & 4 & 0.017 & 4 \\
\hline
\end{tabular}

\section{CONCLUSIONS}

In this paper, $\mathrm{x}$-abilities and attributes based comparison, evaluation and selection of turbine blade material for $\mathrm{CNC}$ turning is presented. Four $\mathrm{x}$-abilities viz. DFM, DFQ, DFE and DFC were simultaneously considered in the evaluation. The CDI obtained from this evaluation proved that ST 12TE was the more suitable material for machining of turbine blades and the next one was ST 174-PH and then ST T17/13W. Though several other design parameters were also considered, the DFX based results showed that ST 12TE was the most suitable material among those considered. This could be attributed to lower surface roughness, less cutting and thrust forces, low machining costs and less environmental impact. The DFX methodology thus allows the users/designers to analyze the different parameters impartially and arrive at an unbiased conclusion.

From the MADM results, it was found that ST 12TE obtained the highest $C_{i}^{*}$ index value of 0.6989. This implied that this alternative had the optimal surface finish, cutting and thrust forces, power consumption, and tool cost as compared to the others tested. The material ST 12TE was found to be the best ranked material among the five materials tested, using MADM-TOPSIS also. Hence, this material was identified as the recommended material for the CNC turning process.

\section{ACKNOWLEDGMENTS}

The material for these experiments is sponsored by TURBOCAM International, India. We like to thank Mr. Savio Carvalho, Director of the organization for providing the material.

\section{REFERENCES}

[1] R. Sandstrom, "An approach to systematic materials selection," Materials and Design, vol. 6, pp. 328-337, 1985.
[2] M. F. Ashby, "Overview No.80: On the engineering properties of materials," Acta Metall Mater, vol. 37, issue 5, pp. 1273-1293, May 1989.

[3] R. V. Rao, "A material selection model using graph theory and matrix approach," Materials Science and Engineering: A, vol. 431, pp. 248-255, 2006.

[4] R. V. Rao and J. P. Davim, "A decision-making framework model for material selection using a combined multiple attribute decision-making method," Int. J. Adv. Manuf. Technol., vol. 35, pp. 751-760, 2008

[5] J. C. Albiñana and C. Vila, "A framework for concurrent material and process selection during conceptual product design stages," Materials \& AMP Design, 2012.

[6] C. P. Kiran, S. Clement, and V. P. Agrawal, "Design for X-abilities of a mechatronic system-a concurrent engineering and graph theoretic approach," Concurrent Engineering Research with Applications, vol. 19, pp. 55-69, 2011.

[7] C. P. Kiran, S. Clement, and V. P. Agrawal, "Coding, evaluation and selection of a mechatronic system," Expert System with Application, vol. 38, pp. 9704-9712, 2011.

[8] T. H. C. Childs, K. Maekawa, T. Obikawa, and Y. Yamane, Metal Machining Theory and Applications, New York: Butterworth Heinemann, Oxford, 2001.

[9] E. M. Trent and P. K. Wright, Metal Cutting, New York: Butterworth Heinemann, Oxford, 2000.

[10] T. Ueda, A. Hosokawa, and K. Yamada, "Effect of oil mist on tool temperature in cutting," Journal of Manufacturing Science and Engineering, vol. 128, pp. 130-135, 2006.

[11] J. P. Davim, "A note on the determination of optimal cutting conditions for surface finish obtained in turning using design of experiments," Journal of Materials Processing Technology, vol. 116, pp. 305-308, 2001.

[12] N. Hirohisha and F. Hideo, "Analysis of environmental impact due to machine tool operation," International Journal of Automation Technology, vol. 3, pp. 49-55, 2009.

[13] S. D. Waigaonkar and B. J. C. Babu, "Application of concurrent engineering for rotationally molded fuel tanks," Rotoworld (Formerly Rotation), vol. 4, pp. 72-77, 2008.

[14] C. P. Kiran, S. Clement, and H. Chelladurai, "Experimental evaluation of quality interactions in material processing," in Proc. International Conference on Product Life cycle, Modeling, Simulation and Synthesis, PLMSS2014, VITS, Vellore, Tamilnadu, India, January 6-8, 2014.

[15] C. P. Kiran and S. Clement, "Surface quality investigation of turbine blade steels for turning process," Measurement, vol. 46, pp. 1875-95, 2013. 


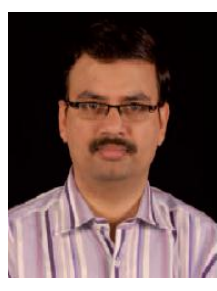

C. Phaneendra Kiran has 10 years of teaching and research experience. Currently he is working as an assistant professor at BITS-Pilani, Hyderabad Campus, Hyderabad, India. He got his BTech degree in mechanical engineering from JNTU, Hyderabad in 2001, ME degree in manufacturing systems engineering and $\mathrm{PhD}$ degree from BITS-Pilani in 2004 and 2013. His research interests are machining, sustainable manufacturing, mechatronics and decision making. He is guiding $\mathrm{BTech}$ and $\mathrm{PhD}$ student(s) in the above mentioned areas.

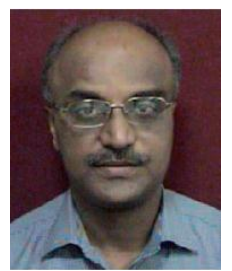

Shibu Clement is working as an assistant professor and the head of the Department of Mechanical Engineering at BITS-Pilani, K K Birla Goa Campus, Goa, India. He completed his graduation in 1991 , post-graduation in 1998, and $\mathrm{PhD}$ degree in 2006 from Bharathiar Univeristy, University of Kerala, and IIT Kanpur respectively. He has published around 12 papers in international journals and conferences. He has guided successfully a large number of B.Tech, M.Tech projects, and supervising current $\mathrm{PhD}$ theses. He has been working extensively in the areas of fluid mechanics, aerodynamics, heat transfer and systems approach. 